Check for updates

Cite this: RSC Adv., 2018, 8, 36745

\title{
Preparation and photocatalytic application of a S, Nd double doped nano- $\mathrm{TiO}_{2}$ photocatalyst $\uparrow$
}

\begin{abstract}
Shuo Wang, (D) * Liming Bai and Xinling Ao
Nowadays, water pollution is getting more and more severe in society, and recently the rational use of photocatalytic technology to treat sewage has become a hot spot for research. Because of the low-cost and environmental friendliness of nano- $\mathrm{TiO}_{2}$, it has attracted widespread attention. In this paper, we dope sulfur and neodymium into nano-titanium dioxide via a sol-gel method. The synthesized $\mathrm{S}, \mathrm{Nd}$ codoped- $\mathrm{TiO}_{2}$ was characterized via transmission electron microscopy, scanning electron microscopy, $\mathrm{X}$-ray diffraction, $\mathrm{X}$-ray photoelectron spectroscopy, EDS and $\mathrm{N}_{2}$ adsorption-desorption isotherms. Then the real-life dye reactive red $(\mathrm{X}-3 \mathrm{~B})$ was used as the target degradant to compare the levels of practicality of single-doped and double-doped photocatalysts. The results showed that the photocatalytic activity of $\mathrm{S}, \mathrm{Nd}$-codoped- $\mathrm{TiO}_{2}$ was significantly higher than that of $\mathrm{Nd}-\mathrm{TiO}_{2}$. The double-doped photocatalyst was transformed from anatase to rutile, and the bandgap was reduced considerably. The responding ability to visible light also increased, so $\mathrm{S}, \mathrm{Nd}$-codoped- $\mathrm{TiO}_{2}$ has obvious advantages and has better degradation efficiency for the target degradation products. Under xenon lamp irradiation and $\mathrm{pH}=4$ conditions, the degradation of reactive red using the new catalyst reached $93.2 \%$. The new catalyst has high practicality and also indicates a new direction for wastewater treatment.
\end{abstract}

Received 13th August 2018 Accepted 22nd October 2018

DOI: $10.1039 / c 8 r a 06778 c$

rsc.li/rsc-advances conduction band. However, the photocatalytic performance of $\mathrm{TiO}_{2}$ is poor due to the extremely short recombination time of photogenerated electrons and electron holes. Therefore, prolonging the photogenerated electron and hole recombination time has become a hot spot in research into $\mathrm{TiO}_{2}$ photocatalysts. Due to the wide bandgap of $\mathrm{TiO}_{2}\left(E_{\mathrm{g}}=3.2 \mathrm{eV}\right)$, it can only be excited by ultraviolet radiation at a wavelength of $387 \mathrm{~nm}$; it can also agglomerate easily with poor dispersion and has a low utilization rate for sunlight. Therefore, researchers have adopted modified or retouched $\mathrm{TiO}_{2}$ to improve defects and improve photocatalytic efficiency. ${ }^{15-20}$ In 2017, Balter Trujillo-Navarrete et al. explained the reasons for lattice distortion caused by $\mathrm{Nd}-\mathrm{TiO}_{2}$, which affects the recombination rate of photoelectrons and holes and improves photocatalytic performance. ${ }^{21}$ In 2018, Thirupathi Boningari used a one-step method to synthesize $\mathrm{S}-\mathrm{TiO}_{2}$ and confirmed that $\mathrm{S}$ doping could effectively reduce the optical band gap of $\mathrm{TiO}_{2}$. The photoresponsive wavelength of $\mathrm{TiO}_{2}$ can not only be extended beyond the visible region, but also the absorption of light in the ultraviolet region can be maintained. ${ }^{22}$ However, many experiments have confirmed that the single doping of $\mathrm{TiO}_{2}$ does not completely increase the utilization of titanium dioxide. Therefore, double-doped photocatalysts and multi-doped photocatalysts have become hot spots for research. ${ }^{23-25} \mathrm{~A}$ large number of studies have found that the rare earth element neodymium is more active in terms of chemical properties, cheaper and more readily available, and can be well combined with titanium dioxide, so it has attracted the attention of
College of Chemistry and Chemical Engineering, Qiqihar University, Qiqihar, Heilongjiang, 161006, P. R. China. E-mail: 345508266@qq.com; Tel: +86 15561926110

$\uparrow$ CCDC \#84-1286 and \#75-1753. For crystallographic data in CIF or other electronic format see DOI: $10.1039 / \mathrm{c} 8 \mathrm{ra} 06778 \mathrm{c}$ 
scholars. The contribution of non-metallic sulfur to the light absorption capacity of titanium dioxide is well known, so combining the advantages of both would be a very meaningful exercise.

Based on these analyses, we first prepared a single-doped photocatalyst $\mathrm{Nd}-\mathrm{TiO}_{2}$ with a low electron-hole recombination rate using a sol-gel method. Then, adopting the same process, $\mathrm{Nd}$ and $\mathrm{S}$ are co-doped into the $\mathrm{TiO}_{2}$ structure to obtain a bifunctional catalyst with a low electron recombination rate and wide photoresponse range. The $\mathrm{S}$ element is doped while controlling the Nd content. The purpose of doing this is to obtain photocatalysts with two advantages. Degradation using $\mathrm{Nd}-\mathrm{TiO}_{2}$ and $\mathrm{S}$, Nd-codoped- $\mathrm{TiO}_{2}$ photocatalysts with diverse contents were investigated using active red as the target degradation product. The results are positive. The doubledoped photocatalyst has significantly higher photodegradation capability than the single-doped photocatalyst, and the double-doped photocatalyst has a broader light response range. This research has provided valuable theoretical exploration of and technical support for the large-scale treatment of dye wastewater.

\section{Experimental}

\subsection{Reagents and apparatus}

Thiourea, tetrabutyl titanate and neodymium nitrate were purchased from Tianjin Fuchen Reagent Factory of China. Reactive red was a product of Tianjin Kaitong Reagent Factory of China. All reagents were commercially available and were not subjected to secondary purification. Infrared spectroscopy was performed using a Perkin Elmer Nicolet-50X FTIR spectrometer (JEOL Ltd., Japan). X-ray diffraction analysis was performed using a Dmax-IIIC X-ray diffractometer (JEOL Ltd., Japan). Structural analysis was performed using a S-4300 field emission scanning electron microscope and a H7650 transmission electron microscope (HITACHI Ltd., Japan). UV-visible spectra of the samples were recorded on a UV-visible DRS instrument (DRS; UV-2450, Shimadzu Co.) using $\mathrm{BaSO}_{4}$ as the standard reference. Adsorption/desorption analysis was performed using an Autosorb 1 physical adsorption-desorption instrument (QUANTACHROME Ltd., America). XRD analysis was performed using a D8 Focus X-ray powder diffractometer (German BrukerAxs). The sample was fluorescently characterized using an F4500 fluorescence spectrophotometer, manufactured by Hitachi, Japan. All $\mathrm{pH}$ values were measured using a $\mathrm{pH}$ indicator manufactured by Beijing Sartorius.

\subsection{The preparation of $\mathrm{S}, \mathrm{Nd}-\mathrm{TiO}_{2}$}

Tetrabutyl titanate $(25 \mathrm{~mL})$ and glacial acetic acid $(4 \mathrm{~mL})$ were dissolved in $34 \mathrm{~mL}$ of anhydrous ethanol, and this mixture was stirred continuously for 30 minutes. The $\mathrm{pH}$ of the solution was then adjusted using dilute hydrochloric acid solution. The $\mathrm{pH}$ of the mixture was adjusted to 3 . The resulting mixture was placed in an ultrasonic bath and irradiated for 10 minutes under a sound wave of $40 \mathrm{kHz}$ to make the mixing more uniform. Four portions of weighed neodymium nitrate $(0.166 \mathrm{~g}$ each) were added to distilled water $(4 \mathrm{~mL})$ and anhydrous ethanol $(17 \mathrm{~mL})$, then thiourea $(0 \mathrm{~g}, 0.170 \mathrm{~g}, 0.340 \mathrm{~g}$ or $0.51 \mathrm{~g})$ was added. Then the $\mathrm{pH}$ was adjusted to 3 with an aqueous solution of hydrochloric acid. The mixture was sonicated at the same intensity. Under magnetic stirring, the neodymium nitrate mixture was added dropwise to the tetrabutyl titanate solution at 1-2 drops per second. After magnetic stirring for $10 \mathrm{~h}$, it was let stand for $10 \mathrm{~h}$. The mixture was then placed in a drying oven at $70{ }^{\circ} \mathrm{C}$ and dried for $2 \mathrm{~h}$, then it was moved into a muffle furnace and calcined for $2 \mathrm{~h}\left(450{ }^{\circ} \mathrm{C}\right)$. Based on the above method, we synthesized photocatalysts with different $\mathrm{S}$ content values.

\subsection{Photocatalytic activity tests}

The photocatalytic activities of the $\mathrm{S}, \mathrm{Nd}-\mathrm{TiO}_{2}$ nanocomposites were evaluated by measuring the absorbance of reactive red solution added to the photocatalysts under sunlight irradiation. In the experiment, the light source was condensed under a cylindrical glass cannula, and each of the outer tubes contained $50 \mathrm{~mL}$ of reactive red solution with an initial concentration of $10 \mathrm{mg} \mathrm{L}^{-1} .15 \mathrm{mg}$ of photocatalyst was added to each test tube. The solid-liquid mixture was magnetically stirred in the dark for $30 \mathrm{~min}$ to bring the photocatalyst to adsorptiondesorption equilibrium. Then the mixture was placed vertically under a $300 \mathrm{~W}$ xenon lamp equipped with an optical transmission filter $(\lambda=365 \mathrm{~nm}) .5 \mathrm{~mL}$ of the mixture was centrifuged at intervals of $20 \mathrm{~min}$ to separate the solid photocatalyst from the solution. The absorbance was measured using a spectrophotometer (TU-1901) at the maximum absorption wavelength, $540 \mathrm{~nm}$, of the reactive red solution, and the decolorization rate was calculated. The solution decolorization rate $(D)$ was calculated via the following formula:

$$
D=\frac{A_{0}-A_{t}}{A_{0}} \times 100 \%
$$

where $A_{0}$ represents the absorbance of the reactive red solution before illumination, and $A_{t}$ represents the absorbance of the reactive red solution after irradiation.

\section{Results \& discussion}

$\mathrm{X}$-ray diffraction patterns of the double-hybrid photocatalyst $\mathrm{S}$, $\mathrm{Nd}-\mathrm{TiO}_{2}$ with different sulfur content are shown in Fig. 1. The S, $\mathrm{Nd}-\mathrm{TiO}_{2}$ samples show diffraction peaks at $2 \theta=25.2^{\circ}, 38.0^{\circ}$, $48.0^{\circ}, 54.3^{\circ}, 55.3^{\circ}, 63.1^{\circ}, 68.7^{\circ}, 70.1^{\circ}$, and $74.9^{\circ}$, corresponding to the (101), (004), (200), (105), (211), (204), (116), (220), and (215) planes of anatase titania. These were confirmed to be from anatase titanium dioxide by comparison with JCPDS card \#841286. In addition, the peaks at $2 \theta=27.0^{\circ}, 41.0^{\circ}, 43.8^{\circ}$, and $56.6^{\circ}$ can be ascribed to the (110), (111), (210), and (220) planes of a rutile titania structure. These were confirmed to be from rutile titanium dioxide by comparison with JCPDS card \#75-1753. Fig. 1a shows the $\mathrm{Nd}-\mathrm{TiO}_{2}$ photocatalyst. This only shows anatase $\mathrm{TiO}_{2}$ characteristics. Fig. 1b-d are double doped photocatalysts with different $S$ doping amounts. The photocatalyst having a sulfur doping amount of $2 \%$ exhibited only anatase 


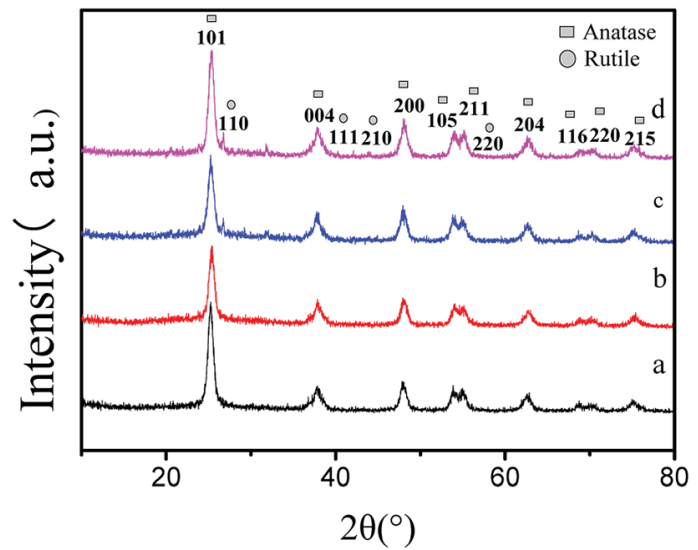

Fig. 1 XRD patterns of (a) $\mathrm{Nd}-\mathrm{TiO}_{2}$, (b) $2 \% \mathrm{~S}, \mathrm{Nd}-\mathrm{TiO}_{2}$, (c) $4 \% \mathrm{~S}, \mathrm{Nd}-$ $\mathrm{TiO}_{2}$, and (d) $6 \% \mathrm{~S}, \mathrm{Nd}-\mathrm{TiO}_{2}$.

characteristics. The photocatalysts having sulfur doping amounts of $4 \%$ and $6 \%$ exhibited mixed crystal forms. In the experiment, we observed that with an increase in the amount of non-metallic sulfur doping, anatase type titanium dioxide gradually changed to rutile type. This may be due to the combined action of sulfur and neodymium to convert the photocatalyst to high stability rutile $\mathrm{TiO}_{2}$. Although the doping of $\mathrm{Nd}$ can inhibit the crystalline phase transition of nano-TiO and increase its thermal stability, an increase in the sulfur content will weaken the effects of neodymium. Because the band gap of the rutile phase is smaller than the forbidden bandwidth of the anatase phase, the absorption spectrum is red-shifted, and the response to visible light is enhanced. Therefore, the double-doped photocatalyst will have significantly higher degradability than the single-doped photocatalyst. The average grain size was calculated using the Scherrer formula: $D=k \lambda / \beta \cos \theta$ ( $D$ is the average grain size; $k$ is a constant of $0.89 ; \lambda$ is the $\mathrm{X}$-ray wavelength, equal to $0.154056 \mathrm{~nm} ; \beta$ is the full width at half maximum; and $\theta$ is the diffraction angle). We can estimate the diameter of $\mathrm{Nd}-\mathrm{TiO}_{2}$ and $\mathrm{S}, \mathrm{Nd}-\mathrm{TiO}_{2}$ particles. The average particle diameter of $\mathrm{Nd}-$ $\mathrm{TiO}_{2}$ was $13.18 \mathrm{~nm} .2 \% \mathrm{~S}, \mathrm{Nd}-\mathrm{TiO}_{2}$ has a particle diameter of $17.66 \mathrm{~nm}, 4 \% \mathrm{~S}, \mathrm{Nd}-\mathrm{TiO}_{2}$ has a particle diameter of $18.11 \mathrm{~nm}$, and $6 \% \mathrm{~S}, \mathrm{Nd}-\mathrm{TiO}_{2}$ has a particle diameter of $18.50 \mathrm{~nm}$. It can be seen that Nd-doped $\mathrm{TiO}_{2}$ shows reduced particle size, and the particle size of double-doped $\mathrm{TiO}_{2}$ is less affected.

The particle size of pure $\mathrm{TiO}_{2}$ is around $50 \mathrm{~nm}$, but the doping of $\mathrm{Nd}$ leads to a decrease in $\mathrm{TiO}_{2}$ grain size. An SEM

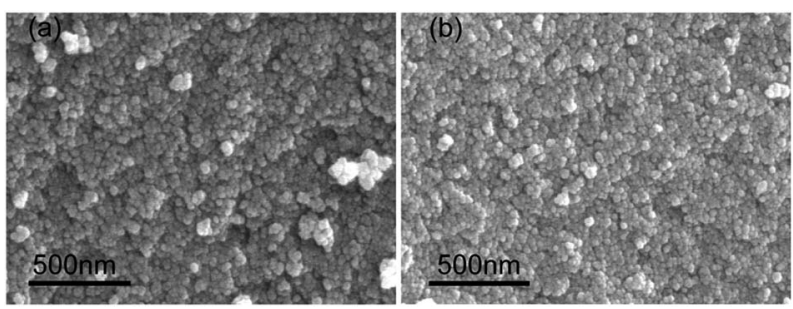

Fig. 2 SEM images of (a) $\mathrm{Nd}-\mathrm{TiO}_{2}$, and (b) $\mathrm{S}, \mathrm{Nd}-\mathrm{TiO}_{2}$.

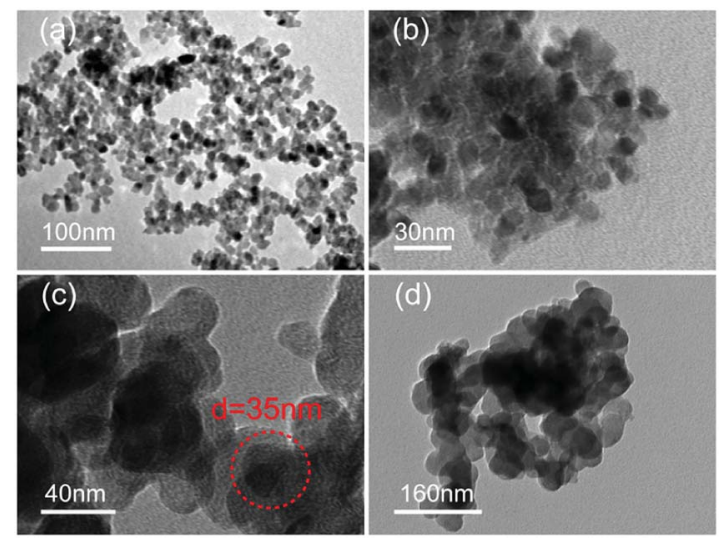

Fig. 3 TEM images of (a) $\mathrm{Nd}-\mathrm{TiO}_{2}$, (b) $2 \% \mathrm{~S}, \mathrm{Nd}-\mathrm{TiO}_{2}$, (c) $4 \% \mathrm{~S}, \mathrm{Nd}-$ $\mathrm{TiO}_{2}$, and (d) $6 \% \mathrm{~S}, \mathrm{Nd}-\mathrm{TiO}_{2}$.

image in Fig. 2 shows as-prepared $\mathrm{Nd}-\mathrm{TiO}_{2}$ (Fig. 2a) with a size of about $15 \mathrm{~nm}$. An SEM image in Fig. 2 also shows as-prepared S, Nd-TiO 2 (Fig. 2b) with a size of about $20 \mathrm{~nm}$. The doped $\mathrm{TiO}_{2}$ is spherical, which effectively reduces the issue of agglomeration and improves the dispersibility. The results show that both single and double doping can better improve the defects of $\mathrm{TiO}_{2}$. Double-doped photocatalyst particles are significantly smaller in diameter than single-doped examples, which provides a basis for the better adsorption of dye molecules.

The TEM images in Fig. 3 show aggregated particles of Nd$\mathrm{TiO}_{2}$ (Fig. 3a) and $\mathrm{S}, \mathrm{Nd}-\mathrm{TiO}_{2}$ (Fig. 3b-d), with particle sizes of $20 \mathrm{~nm}$. In the $\mathrm{Nd}-\mathrm{TiO}_{2}$ and $\mathrm{S}, \mathrm{Nd}$-codoped- $-\mathrm{TiO}_{2}$ photocatalysts, the black $\mathrm{Nd}$ is more homogeneously dispersed in the $\mathrm{TiO}_{2}$, which obviously improves the defect of $\mathrm{TiO}_{2}$ agglomerating easily. Fig. 3b-d show double doped photocatalysts with different S concentrations. In Fig. 3c, the $4 \% \mathrm{~S}$ doped double doped photocatalyst disperses more evenly. Compared with the other photocatalysts, the doping of Nd and S has less effect on $\mathrm{TiO}_{2}$, and all crystal grains are mainly spherical. The gap between crystal grains is homogeneous and the particle diameter is about $20 \mathrm{~nm}$.

Fig. 4 shows XPS analysis of the $\mathrm{S}, \mathrm{Nd}-\mathrm{TiO}_{2}$ photocatalyst. Since the photocatalytic activity of $\mathrm{TiO}_{2}$ is affected by the type and content of doping elements, the chemical composition of $\mathrm{S}$, $\mathrm{Nd}-\mathrm{TiO}_{2}$ is analyzed via XPS spectroscopy to detect whether $\mathrm{S}$ and $\mathrm{Nd}$ are co-doped into the $\mathrm{TiO}_{2}$ lattice. The XPS spectrum shows that the photocatalyst $\mathrm{S}, \mathrm{Nd}-\mathrm{TiO}_{2}$ is mainly composed of five elements: $\mathrm{S}, \mathrm{Nd}, \mathrm{Ti}, \mathrm{O}$ and $\mathrm{C}$. The $\mathrm{Ti}$ and $\mathrm{O}$ elements are derived from nano-titanium dioxide, the $\mathrm{S}$ and $\mathrm{Nd}$ elements are derived from the doping solution, and $\mathrm{C}$ is derived from organic precursor calcination residue. The binding energies of the $\mathrm{Ti}$ 2p1/2 peak and the Ti 2p3/2 peak are $464 \mathrm{eV}$ and $457 \mathrm{eV}$, respectively; they differ by $7 \mathrm{eV}$, indicating that Ti is mainly present in the form of $\mathrm{Ti}^{4+}$. The $\mathrm{Ti} 2 \mathrm{p} 3 / 2$ binding energy peak of pure $\mathrm{TiO}_{2}$ is $459 \mathrm{eV}$. This indicates that the doping of $\mathrm{TiO}_{2}$ by the two elements $\mathrm{S}$ and $\mathrm{Nd}$ causes the chemical environment of Ti to change, resulting in a chemical shift. $531 \mathrm{eV}$ is a characteristic peak of a surface hydroxyl oxygen. This exists in the form of an $\mathrm{Nd}-\mathrm{O}$ bond or $\mathrm{Nd}_{2} \mathrm{O}_{3}$ at $529 \mathrm{eV}$. The metal $\mathrm{Nd}$ has a large 

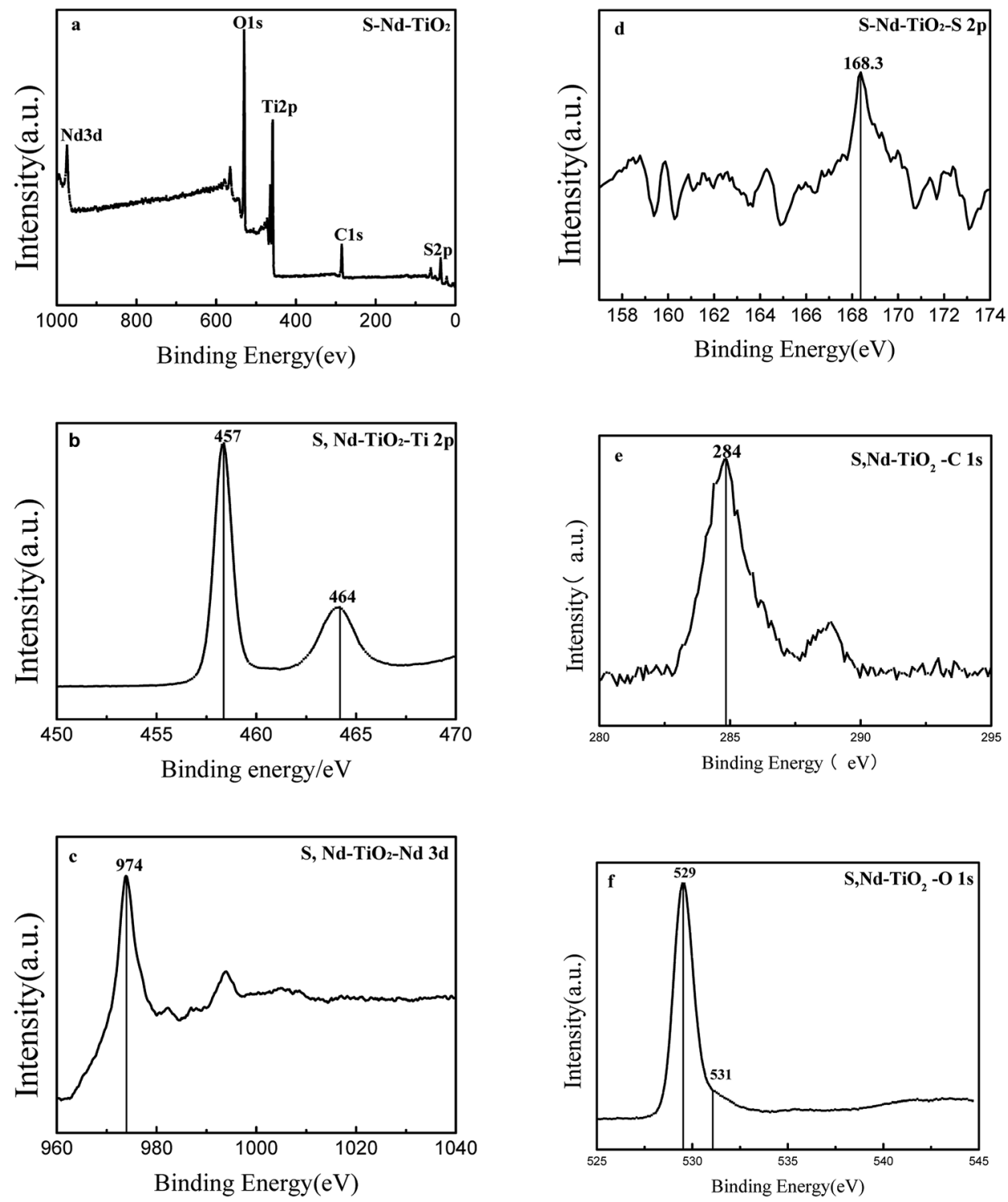

Fig. 4 XPS spectra of (a) S, Nd- $\mathrm{TiO}_{2}$ : (b) the Ti $2 \mathrm{p}$ band, (c) the $\mathrm{Nd} 3 \mathrm{~d}$ band, (d) the $\mathrm{S} 2 \mathrm{p}$ band, (e) the $\mathrm{C}$ 1s band, and (f) the $\mathrm{O} 1 \mathrm{~s}$ band.

radius and is difficult to dope into $\mathrm{TiO}_{2}$. Regarding the doping of sulfur, $\mathrm{S} 2 \mathrm{p}$ has a peak at $168 \mathrm{eV}$, indicating the doping of $\mathrm{S}$ in the $\mathrm{TiO}_{2}$ lattice, possibly in the form of O-Ti-S. This is why Sdoped $\mathrm{TiO}_{2}$ has a visible light response. For $\mathrm{S}, \mathrm{Nd}-\mathrm{TiO}_{2}$ particles, the binding energy of $\mathrm{Nd} 3 \mathrm{~d}$ is located at $974 \mathrm{eV}$. In the $\mathrm{S}$, $\mathrm{Nd}-\mathrm{TiO}_{2}$ photocatalyst, the $\mathrm{Ti}$ content is $19.53 \%$, the $\mathrm{O}$ content is $53.01 \%$, the $\mathrm{Nd}$ content is $1.08 \%$, the $\mathrm{S}$ content is $0.12 \%$, and the $\mathrm{C}$ content is $26.25 \%$. Of these, carbon is mainly derived from the calcination of the photocatalyst, and the carbon content is too high due to the XPS analysis background. Therefore, we have reason to believe that $\mathrm{Nd}$ and $\mathrm{S}$ are successfully doped into the $\mathrm{TiO}_{2}$ lattice.

Fig. 5 shows EDS spectra of the $\mathrm{S}, \mathrm{Nd}$-codoped-TiO ${ }_{2}$ photocatalyst. Analyzing these, the four elements $\mathrm{Ti}, \mathrm{O}, \mathrm{Nd}$ and $\mathrm{S}$ are derived from the preparation of the photocatalyst, and the $\mathrm{C}$ element is derived from the calcination of the precursor. The results show that the element content is in the order of $\mathrm{Ti}>\mathrm{C}>$ $\mathrm{O}>\mathrm{Nd}>\mathrm{S}$, from high to low. It can be found from the test that in the double-doped photocatalyst, the content of the sulfur element is significantly lower than that of the doping amount, and the content of the $\mathrm{Nd}$ element is level with the doping

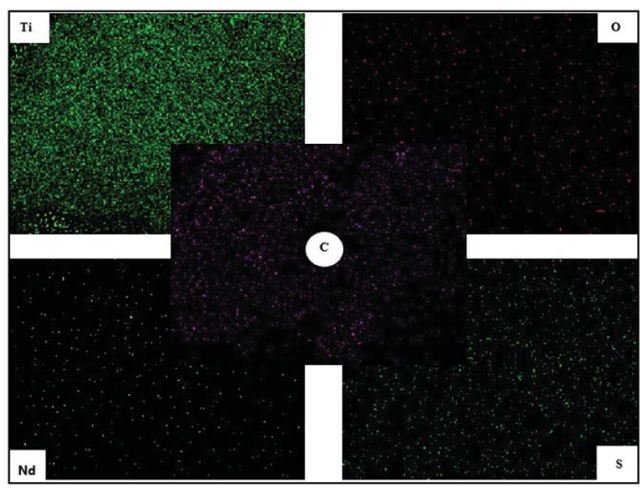

Fig. 5 EDS images of $\mathrm{S}, \mathrm{Nd}-\mathrm{TiO}_{2}$. 


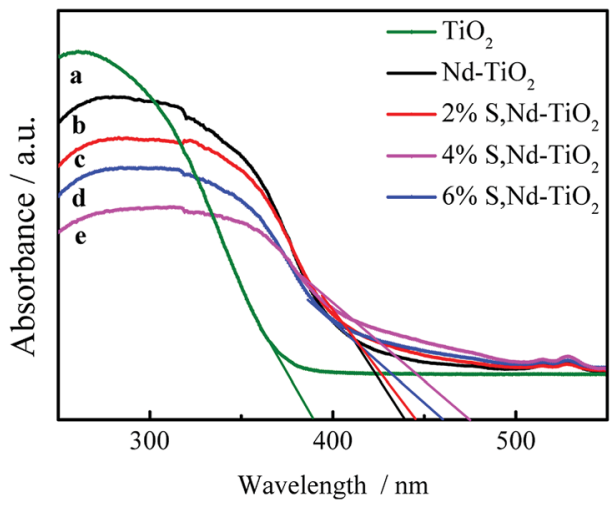

Fig. 6 DRS spectra of single and double-doped photocatalysts: (a) $\mathrm{TiO}_{2} ;$ (b) $\mathrm{Nd}-\mathrm{TiO}_{2} ;$ (c) $2 \% \mathrm{~S}, \mathrm{Nd}-\mathrm{TiO}_{2} ;$ (d) $6 \% \mathrm{~S}, \mathrm{Nd}-\mathrm{TiO}_{2}$; and (e) $4 \% \mathrm{~S}$, $\mathrm{Nd}-\mathrm{TiO}_{2}$.

amount. This may be because $\mathrm{Nd}^{3+}$ is difficult to insert into the $\mathrm{TiO}_{2}$ crystal lattice, and $\mathrm{S}^{6+}$ can replace $\mathrm{Ti}^{4+}$ in the $\mathrm{TiO}_{2}$ crystal lattice, so the $\mathrm{S}$ element content detected by EDS and XPS is low.

DRS absorption spectra provided information about the wavelength region in which the catalyst absorbs light (Fig. 6). In the ultraviolet region, $\mathrm{TiO}_{2}$ has the largest light absorption capabilities, which are significantly higher than those of the double-doped photocatalyst. The synthesized $\mathrm{S}, \mathrm{Nd}-\mathrm{TiO}_{2}$ composites exhibited significantly stronger absorption compared to $\mathrm{TiO}_{2}$ in the visible region. The synthesized $4 \% \mathrm{~S}$, $\mathrm{Nd}-\mathrm{TiO}_{2}$ composite exhibited a clear absorption edge at approximately $476 \mathrm{~nm}$ in the visible light region, and a band gap energy of $2.61 \mathrm{eV}$ was estimated via the equation: $\lambda_{\mathrm{g}}=1240 /$ $E_{\mathrm{g}}$. Similarly, the forbidden band width of pure $\mathrm{TiO}_{2}$ is $3.16 \mathrm{eV}$. In the infrared region, the four photocatalysts exhibited good light absorption capacity, and S, Nd double-doped photocatalysts showed significantly higher values than the singledoped photocatalyst. Pure $\mathrm{TiO}_{2}$ can only absorb ultraviolet light, so the peak in the infrared region is caused by Nd doping. With an increase in S content, the peak increases correspondingly, indicating that $\mathrm{S}$ doping can promote the absorption of visible light by the photocatalyst. The experimental results show that the $\mathrm{TiO}_{2}$ and $\mathrm{Nd}-\mathrm{TiO}_{2}$ calcined samples are white, while for the $\mathrm{S}, \mathrm{Nd}-\mathrm{TiO}_{2}$ samples, as the $\mathrm{S}$ content increases, the light yellow color gradually deepens, which is consistent with corresponding literature reports. ${ }^{26,27}$

The nitrogen adsorption and desorption isotherms in Fig. 7 were used to characterize the structure of $\mathrm{S}, \mathrm{Nd}-\mathrm{TiO}_{2}$. It shows a type $\mathrm{V}$ isotherm. $\mathrm{S}, \mathrm{Nd}-\mathrm{TiO}_{2}$ shows a hysteresis loop at $P / P_{0}=$ $0.45-0.8$, indicating that the new catalyst has mesopores, and there is no obvious inflexion point at $P / P_{0}=0.05$, which suggests that there are no micropores or very few micropores in the new material. From pore size distribution curve analysis, it is shown that the pore sizes of $\mathrm{S}, \mathrm{Nd}-\mathrm{TiO}_{2}$ are mainly distributed between $30-50 \mathrm{~nm}$, which is consistent with the TEM analysis results. The pore size of $\mathrm{TiO}_{2}$ is between 50 and $90 \mathrm{~nm}$, and the specific surface area is small. When $\mathrm{S}$ and $\mathrm{Nd}$ are doped into $\mathrm{TiO}_{2}$, the pore size decreases and the pore volume decreases accordingly. The specific surface area was significantly higher than that of $\mathrm{TiO}_{2}$, and the specific surface area was

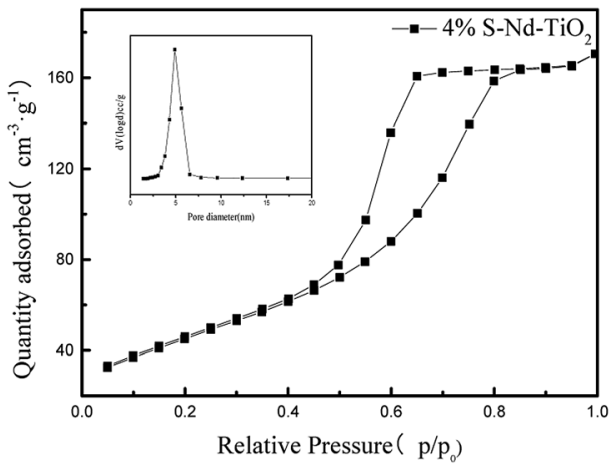

Fig. 7 The nitrogen adsorption-desorption isotherm and pore size distributions curve of $4 \% \mathrm{~S}, \mathrm{Nd}-\mathrm{TiO}_{2}$.

about 3 times that of pure $\mathrm{TiO}_{2}$. The specific surface area of the double-doped photocatalyst is $166.8 \mathrm{~m}^{2} \mathrm{~g}^{-1}$, and the specific surface area of pure $\mathrm{TiO}_{2}$ is $56.5 \mathrm{~m}^{2} \mathrm{~g}^{-1}$. This shows that doping with $\mathrm{Nd}$ and $\mathrm{S}$ can suppress the lattice growth of $\mathrm{TiO}_{2}$, increase the specific surface area, and increase the photocatalytic activity (Table 1).

Fig. 8 shows fluorescence spectra analysis of the semiconductor $\mathrm{TiO}_{2}$ and the new catalysts. This was used to effectively investigate the recombination of electrons and holes on the surface of $\mathrm{TiO}_{2}$ before and after modification. The results show that the fluorescence intensity of pure $\mathrm{TiO}_{2}$ is large, and electrons and holes are easily recombined. With the doping of neodymium and sulfur, the fluorescence intensity of the composite decreases and the electron-hole recombination rate decreases. The doping of sulfur has no effect. The reason for this phenomenon is that the rare earth metal Nd forms a Ti-O-

Table 1 The specific surface area and pore size distribution parameters of $\mathrm{TiO}_{2}$ and $\mathrm{S}, \mathrm{Nd}-\mathrm{TiO}_{2}$

\begin{tabular}{lllll}
\hline Sample & $\begin{array}{l}\text { Surface area } \\
\left(\mathrm{m}^{2} \mathrm{~g}^{-1}\right)\end{array}$ & $\begin{array}{l}\text { Pore volume } \\
\left(\mathrm{cm}^{3} \mathrm{~g}^{-1}\right)\end{array}$ & $\begin{array}{l}\text { Crystallite } \\
\text { size }(\mathrm{nm})\end{array}$ & $P / P_{0}$ \\
\hline $\mathrm{TiO}_{2}$ & 56.50 & 0.9918 & 38.29 & 0.99915 \\
$\mathrm{~S}, \mathrm{Nd}-\mathrm{TiO}_{2}$ & 166.82 & 0.2644 & 20.56 & 0.99578
\end{tabular}

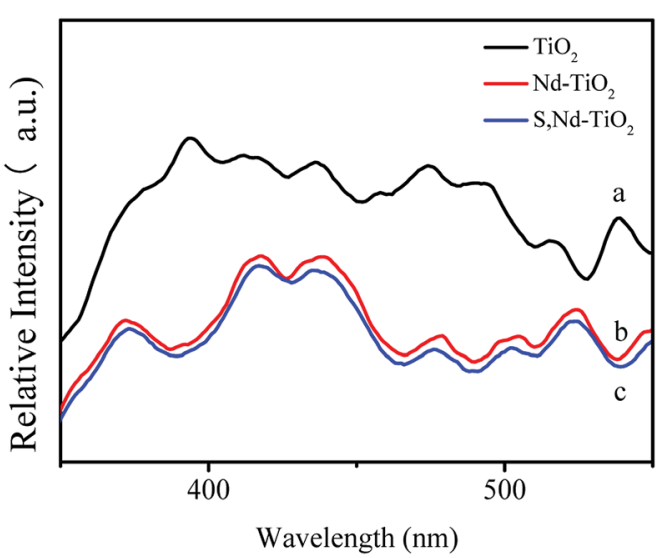

Fig. $8 \mathrm{PL}$ fluorescence spectra analysis of each sample: (a) $\mathrm{TiO}_{2}$; (b) $\mathrm{Nd}-\mathrm{TiO}_{2} ;$ and (c) $\mathrm{S}, \mathrm{Nd}-\mathrm{TiO}_{2}$. 


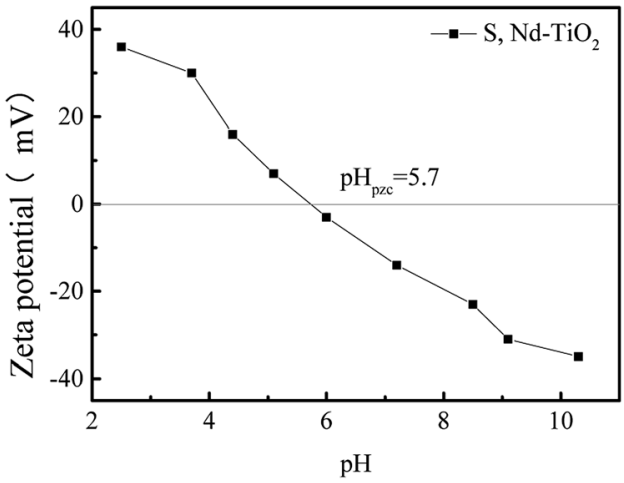

Fig. 9 The point of zero charge $\left(\mathrm{pH}_{\mathrm{pzc}}\right)$ for the $\mathrm{S}, \mathrm{Nd}-\mathrm{TiO}_{2}$ catalyst.

$\mathrm{Nd}$ bond around $\mathrm{TiO}_{2}$. This is uniformly dispersed in the form of an oxide on the surface of $\mathrm{TiO}_{2}$ or in the octahedral gaps of the $\mathrm{TiO}_{2}$ lattice. In order to compensate for this charge imbalance, the surface of $\mathrm{TiO}_{2}$ will adsorb more hydroxyl groups and promote the photocatalytic oxidation of $\mathrm{TiO}_{2}$. This not only effectively separates photogenerated electrons and holes, but also generates more active hydroxyl groups, improving the photocatalytic performance of nano- $\mathrm{TiO}_{2}$.

Fig. 9 shows the zeta potential values of $\mathrm{S}, \mathrm{Nd}-\mathrm{TiO}_{2}$ photocatalysts under different $\mathrm{pH}$ conditions. The point at which the potential is zero is called the isoelectric point $\left(\mathrm{pH}_{\mathrm{pzc}}\right)$. The adsorbent surface charge is neutral when $\mathrm{pH}=\mathrm{pH}_{\mathrm{pzc}}$. The electrostatic force between the surface of the adsorbent and the ions is negligible. The double-doped photocatalyst $\mathrm{S}, \mathrm{Nd}-\mathrm{TiO}_{2}$ has an isoelectric point of about 5.7. When the $\mathrm{pH}$ is less than 5.7 , the zeta potential is greater than zero and the catalyst surface is positively charged. When the $\mathrm{pH}$ is greater than 5.7 , the zeta potential is less than zero and the catalyst surface is negatively charged. Reactive red is an anionic dye, and the double-doped photocatalyst shows better adsorption effects due to electrostatic attraction.

\section{Photocatalytic activity}

\subsection{Photocatalyst degradation tests}

The photocatalytic activities of the $\mathrm{S}, \mathrm{Nd}-\mathrm{TiO}_{2}$ nanocomposites were investigated by measuring the relationship between the degradation rate of reactive red solution irradiated by a xenon lamp and the irradiation time. In the degradation formula, $C$ is the initial concentration of reactive red and $C_{t}$ is the concentration after a fixed reaction time. The comparative experiment is degradation experiments conducted with the photocatalyst $\mathrm{Nd}-\mathrm{TiO}_{2}$. Stirring under dark conditions is indispensable prior to photocatalytic degradation. A quantitative amount of photocatalyst was added to the target degradant solution and magnetically stirred for $30 \mathrm{~min}$ to achieve adsorption and analytical equilibrium. For all samples, adsorption appeared to be of little use and the reactive red solution concentration did not change. But as the irradiation time increased, all samples degraded the reactive red solution. After 120 min using the single-doped photocatalyst, the degradation rate of reactive red reached about $90 \%$. Comparing the single-doped and doubledoped photocatalysts, the double-doped photocatalysts have better abilities to degrade reactive red than the single-doped photocatalyst. So, the S doping described can significantly improve the catalyst activity. In addition, the photocatalytic activities of the single-doped photocatalyst $\mathrm{Nd}-\mathrm{TiO}_{2}$ and the double-doped photocatalyst $\mathrm{S}, \mathrm{Nd}-\mathrm{TiO}_{2}$ were analyzed via the Langmuir-Hinshelwood kinetic model. The kinetic formula is as follows:

$$
-\ln \frac{C_{t}}{C_{0}}=k t
$$

In the formula, $C_{0}$ is the initial concentration before the reactive red solution is degraded, and $C_{t}$ is the concentration of the reactive red solution at different time points. The linear relationships between $\left(C_{t} / C_{0}\right)$ and $-\ln \left(C_{t} / \mathrm{C}_{0}\right)$ and the irradiation time are shown in Fig. 10 and 11. The rate constants of S, Nd$\mathrm{TiO}_{2}$ were higher than that of $\mathrm{Nd}-\mathrm{TiO}_{2}$. The above results indicated that $2 \% \mathrm{~S}, \mathrm{Nd}-\mathrm{TiO}_{2}, 4 \% \mathrm{~S}, \mathrm{Nd}-\mathrm{TiO}_{2}$, and $6 \% \mathrm{~S}, \mathrm{Nd}-$ $\mathrm{TiO}_{2}$ exhibited higher photocatalytic activity than $\mathrm{Nd}-\mathrm{TiO}_{2}$. This is because $\mathrm{Nd}$ element doping prolongs the time of recombination of electrons and holes compared to pure $\mathrm{TiO}_{2}$. Compared with $\mathrm{Nd}-\mathrm{TiO}_{2}$, the doping of $\mathrm{S}, \mathrm{Nd}-\mathrm{TiO}_{2}$ broadens the light absorption range of nano- $\mathrm{TiO}_{2}$. And $4 \% \mathrm{~S}, \mathrm{Nd}-\mathrm{TiO}_{2}$ presented a slightly higher rate constant than $2 \% \mathrm{~S}, \mathrm{Nd}-\mathrm{TiO}_{2}$ and $6 \% \mathrm{~S}$, $\mathrm{Nd}-\mathrm{TiO}_{2}$. The degradation percentage of the reactive red solution by $4 \% \mathrm{~S}, \mathrm{Nd}-\mathrm{TiO}_{2}$ photocatalyst after 160 minutes was $90.4 \%$. The reactive red solution is almost completely decolorized, and the double-doped photocatalyst exhibits very high photocatalytic ability. The degradation rate of reactive red using $\mathrm{Nd}-\mathrm{TiO}_{2}$ was $0.0082 \mathrm{~min}^{-1}$. The degradation rates of reactive red using $2 \% \mathrm{~S}, \mathrm{Nd}-\mathrm{TiO}_{2}$ and $6 \% \mathrm{~S}, \mathrm{Nd}-\mathrm{TiO}_{2}$ were $0.0131 \mathrm{~min}^{-1}$ and $0.0135 \mathrm{~min}^{-1}$, respectively. Of the different samples, the $4 \%$ $\mathrm{S}, \mathrm{Nd}-\mathrm{TiO}_{2}$ photocatalyst had the highest degradation rate towards reactive red solution, $0.0169 \mathrm{~min}^{-1}$. The rate constants of the $\mathrm{S}, \mathrm{Nd}-\mathrm{TiO}_{2}$ nanocomposites were higher than that of $\mathrm{Nd}-$ $\mathrm{TiO}_{2}\left(0.0082 \mathrm{~min}^{-1}\right)$. The above results indicate that $2 \% \mathrm{~S}, \mathrm{Nd}-$ $\mathrm{TiO}_{2}, 4 \% \mathrm{~S}, \mathrm{Nd}-\mathrm{TiO}_{2}$ and $6 \% \mathrm{~S}, \mathrm{Nd}-\mathrm{TiO}_{2}$ exhibited higher photocatalytic activity than $\mathrm{Nd}-\mathrm{TiO}_{2}$, which should be attributed to their bigger light absorption ranges and excellent adsorption performances. And $4 \% \mathrm{~S}, \mathrm{Nd}-\mathrm{TiO}_{2}$ presented

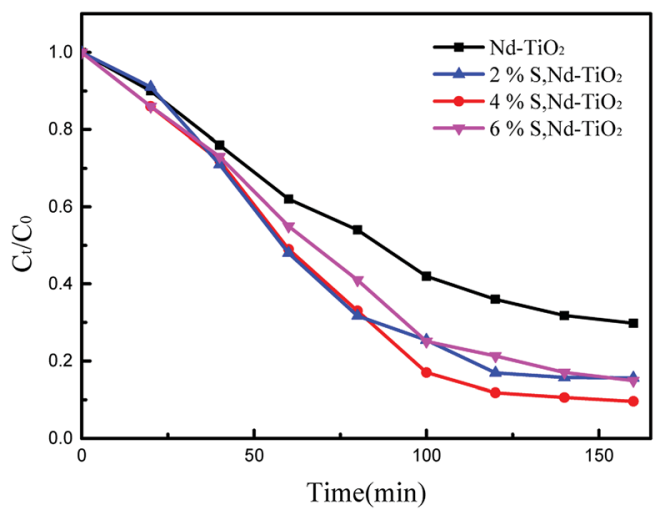

Fig. 10 Photocatalytic degradation of reactive red over $\mathrm{S}, \mathrm{Nd}-\mathrm{TiO}_{2}$. 


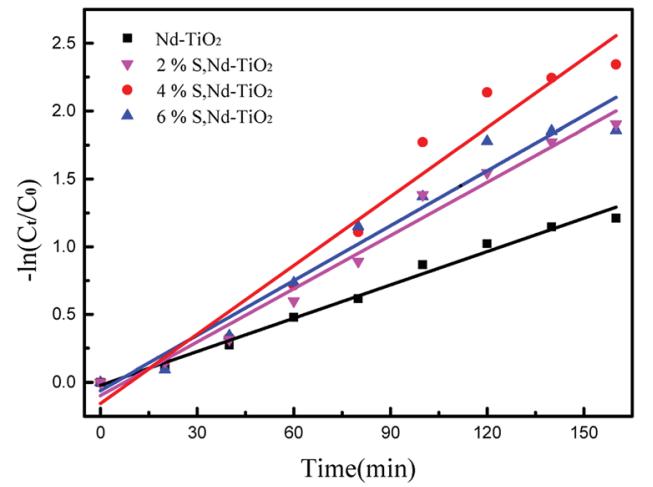

Fig. 11 Plots of $-\ln \left(C_{t} / C_{0}\right)$ versus irradiation time for the degradation of reactive red solution over $\mathrm{S}, \mathrm{Nd}-\mathrm{TiO}_{2}$.

a slightly higher rate constant than $2 \% \mathrm{~S}, \mathrm{Nd}-\mathrm{TiO}_{2}$ and $6 \% \mathrm{~S}$, $\mathrm{Nd}-\mathrm{TiO}_{2}$. In experiments, we chose the optimal doping amount of $\mathrm{Nd}$ as a basic quantity. The doping of different $\mathrm{S}$ content values $(2 \%, 4 \%$ and $6 \%)$ widens the light absorption range of $\mathrm{TiO}_{2}$. Too little $\mathrm{S}$ cannot modify $\mathrm{TiO}_{2}$ very well, and too much S cannot enter the lattice of $\mathrm{TiO}_{2}$, so $4 \% \mathrm{~S}, \mathrm{Nd}-\mathrm{TiO}_{2}$ has the best photocatalytic efficiency.

\subsection{Effect of $\mathrm{pH}$ on the degradation rates of the catalysts}

Whether $\mathrm{C}_{\mathrm{H}^{+}}$in solution affects photocatalytic experiments is a problem we must consider. So, we conducted photocatalytic tests at different $\mathrm{pH}$ values. We chose $4 \% \mathrm{~S}, \mathrm{Nd}-\mathrm{TiO}_{2}$ as a photocatalyst to perform $\mathrm{pH}$ tests. After the catalyst was added to solution, the $\mathrm{pH}$ of the solution was adjusted to $2,4,6,8$, or 10 . After a certain amount of reactive red solution was sampled every 20 minutes, the absorbance was measured, and the degradation rate was calculated. We conclude that the doubledoped photocatalyst has a wide $\mathrm{pH}$ response range, and the catalyst has the best degradation efficiency at $\mathrm{pH}=4$. Under acidic conditions, the catalyst can better absorb dye molecules on the surface. In the presence of hydroxyl radicals and the presence of suitable amounts of $\mathrm{H}^{+}$, the reactive red $(\mathrm{X}-3 \mathrm{~B})$ molecule is eventually decomposed into small groups $\left(\mathrm{NO}_{3}{ }^{-}\right.$, $\mathrm{N}_{2}, \mathrm{H}_{2} \mathrm{O}, \mathrm{CO}_{2}$, etc.). When it is exposed to light, the catalyst shows good ability to degrade reactive red. Under alkaline conditions, the reactive red dye molecules cannot be stably present, so the degradation rates of the catalysts are low. However, when the solution is alkaline, the double-doped photocatalysts still show more than $65 \%$ degradation. Therefore, the double-doped photocatalyst will have a wider $\mathrm{pH}$ response range and higher application value.

\subsection{Photocatalytic repetition experiments}

The multiple use of photocatalysts is important for practical value. Photocatalysts that retain their photocatalytic abilities after repeated degradation experiments are extremely rare. In this experiment, after the end of the first photocatalysis experiment, the upper liquid was poured out and the lower solid catalyst was collected and dried. The photocatalyst was replenished before the next photocatalytic experiment, so that

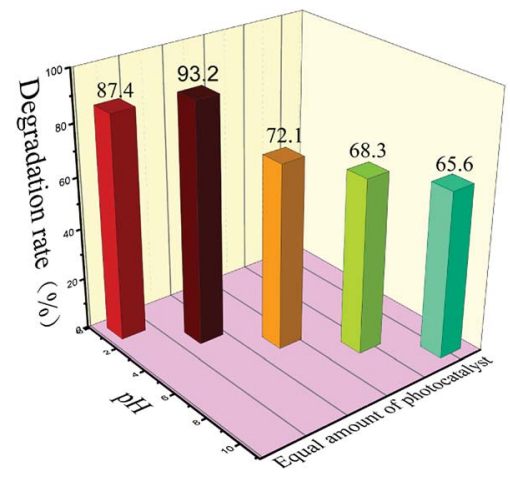

Fig. 12 The photocatalytic degradation of reactive red solution by $\mathrm{S}$, $\mathrm{Nd}$-codoped- $\mathrm{TiO}_{2}$ under different $\mathrm{pH}$ conditions.

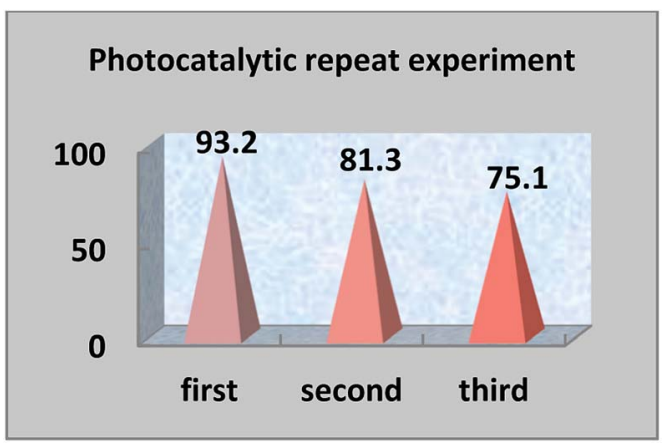

Fig. 13 Photocatalyst reusability efficiency.

the photocatalytic experiment was carried out with the same amount of photocatalysts. Under the same light degradation conditions, the same concentration of reactive red solution was degraded again, and the degradation rate was calculated again. The photocatalytic degradation experiment was repeated three times to judge the reusability. In the experiment, we found that the photocatalyst $\mathrm{S}, \mathrm{Nd}-\mathrm{TiO}_{2}$ has good reusability. As the photocatalyst is reused, the photocatalytic efficiency is lowered. The first cycle photocatalytic degradation amount reached $93 \%$, the second cycle photocatalytic degradation amount reached $81 \%$, and the third cycle photocatalytic degradation amount reached $75 \%$. From the above results, it is shown that the double-doped photocatalyst $\mathrm{S}, \mathrm{Nd}-\mathrm{TiO}_{2}$ has a high practical reusability value in active red solution (Fig. 12 and 13).

\subsection{Photocatalytic mechanism}

It is well known that the electron and hole recombination times determine the photocatalytic activities of catalysts, and the doping of Nd can effectively prolong the recombination time. The doping of an $\mathrm{S}$ element can effectively broaden the $\mathrm{TiO}_{2}$ light absorption range and move this to the visible light region. Therefore, the $\mathrm{S}, \mathrm{Nd}-\mathrm{TiO}_{2}$ double-doped photocatalyst combines the above advantages and exhibits excellent photocatalytic activity through testing. In the experiments, photocatalysis produces a large number of hydroxyl radicals, which can decompose organic matter into small molecules. The decomposed small molecule products of reactive red solution 


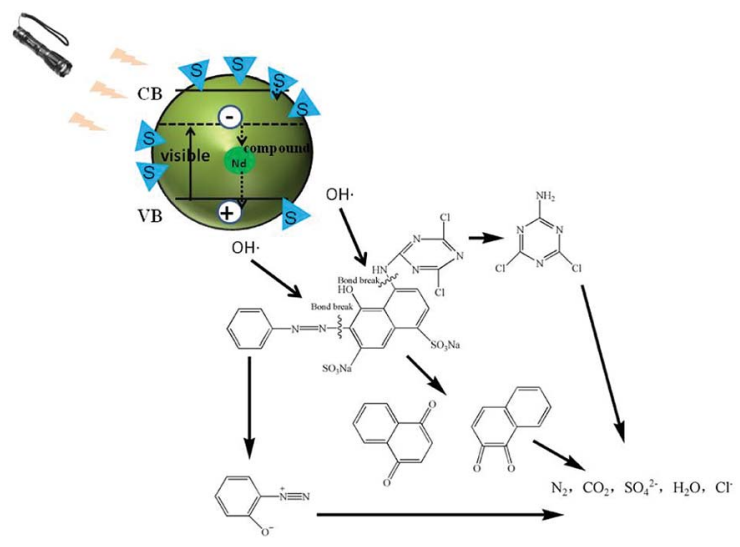

Fig. 14 Photocatalytic mechanism diagram.

after illumination are shown in Fig. 14. This coincides with the principle of hydroxyl radical degradation of organic matter reported in a large amount of literature. Single-doped photocatalysts still have limitations regarding the degradation of dyes and need improvement. Double-doped photocatalysts combine the two advantages and ultimately decompose the dye molecules into $\mathrm{CO}_{2}$ and $\mathrm{H}_{2} \mathrm{O}$. This composite material has successfully improved the defects of $\mathrm{TiO}_{2}$, and the low-consumption method has allowed the degradation of a practical dye solution, which provides a certain forward-looking route for real industry applications.

\section{Conclusions}

$\mathrm{S}$, Nd-codoped- $\mathrm{TiO}_{2}$ was prepared via a sol-gel method. The results of catalyst characterization show that the double-doped photocatalyst can effectively broaden the photoresponse range of $\mathrm{TiO}_{2}$. From the EDS and XPS results, $\mathrm{Nd}$ and $\mathrm{S}$ were successfully doped into $\mathrm{TiO}_{2}$. The $\mathrm{S}, \mathrm{Nd}$-codoped-TiO ${ }_{2}$ photocatalyst has a large specific surface area: $S_{\mathrm{BET}}=166.82 \mathrm{~m}^{2} \mathrm{~g}^{-1}$. Compared with many studies, our synthesized double-doped photocatalysts have higher degradation efficiencies. ${ }^{28-30}$ The new photocatalysts improve the dispersibility of $\mathrm{TiO}_{2}$ and enhance its characteristics regarding ease of agglomeration. The degradation results show that the photodegradation of reactive red solution reached $93.2 \%$ within 160 min using the $S$, Nd co-doped photocatalyst. The degradation of reactive red solution using $\mathrm{Nd}-\mathrm{TiO}_{2}$ after 160 minutes was 70\%. The doubledoped photocatalysts have significantly higher degradation abilities than the single-doped photocatalyst. The reason is that the doping of S and Nd not only broadens the light absorption range of $\mathrm{TiO}_{2}$, but also reduces the recombination rate of electrons and holes. And the new photocatalyst has high stability and reusability. The double-doped photocatalyst is a promising photocatalytic material, which provides a great approach for solving water pollution issues with low consumption and high efficiency.

\section{Conflicts of interest}

There are no conflicts to declare.

\section{Acknowledgements}

This work was supported by the National Natural Science Foundation of China [grant number 21776144].

\section{Notes and references}

1 S. Zong, W. Wei, H. Cui, Z. Jiang, X. Lü, M. Zhang and J. Xie, Mater. Res. Innovations, 2015, 19, 361-367.

2 T. Ochiai, T. Fukuda, K. Nakata, T. Murakami, D. A. Tryk, Y. Koide and A. Fujishima, Appl. Electrochem., 2010, 40, 1737-1742.

3 M. S. Dieckmann and K. A. Gray, Water Res., 2016, 30, 11691183.

4 D. González, E. Cueto, F. Chinesta, P. Díez and A. Huerta, J. Phys. Chem. C, 2016, 117, 1955-1962.

5 Z. Zhu, H. Pan, M. Murugananthan, J. Gong and Y. Zhang, Appl. Catal., B, 2018, 232, 19-25.

6 H. K. Seo, C. M. Elliott and S. G. Ansari, J. Nanosci. Nanotechnol., 2012, 12, 6996-7001.

7 H. Barndõk, D. Hermosilla, L. Cortijo, C. Negro and Á. Blanco, J. Adv. Oxid. Technol., 2016, 15, 125-132.

8 J. Keleher, J. Bashant, N. Heldt, L. Johnson and Y. Li, World J. Microbiol. Biotechnol., 2002, 18, 133-139.

9 A. Fujishima and K. Honda, Nature, 1972, 238, 37-38.

10 U. Diebold, Surf. Sci. Rep., 2003, 48, 53-229.

11 K. M. Reza, A. Kurny and F. Gulshan, Appl. Water Sci., 2017, 7, 1569-1578.

12 S. Garcia-Segura and E. Brillas, J. Photochem. Photobiol., C, 2017, 31, 1-35.

13 V. Binas, D. Venieri, D. Kotzias and G. Kiriakidis, Journal of Materiomics, 2017, 3, 3-16.

14 D. Zhao and C. F. Yang, Renewable Sustainable Energy Rev., 2016, 54, 1048-1059.

15 L. Hu, G. Zeng, G. Chen, H. Dong, Y. Liu, J. Wan, A. Chen, Z. Guo, M. Yan, H. Wu and Z. Yu, J. Hazard. Mater., 2016, 301, 106-118.

16 M. Reli, P. Huo, M. Šihor, N. Ambrožová, I. Troppová, L. Matějová, J. Lang, L. Svoboda, P. Kuśtrowski, M. Ritz, P. Praus and K. Kočí, J. Sol-Gel Sci. Technol., 2017, 43, 8564-8573.

17 S. Demirc, T. Dikici, M. Yurddaskal, S. Gultekin, M. Toparli and E. Celik, Appl. Surf. Sci., 2016, 390, 591-601.

18 W. Yan, S. M. Mahurin, Z. Pan, S. H. Overbury and S. Dai, J. Am. Chem. Soc., 2005, 127, 10480-10481.

$19 \mathrm{Z} . \mathrm{Xu}$ and J. Yu, Nanoscale, 2011, 3, 3138-3144.

20 C. Wang, L. Yin, L. Zhang, N. Liu, N. Lun and Y. Qi, ACS Appl. Mater. Interfaces, 2010, 2, 3373-3377.

21 B. Trujillo-Navarrete, M. del Pilar Haro-Vázquez, R. María Félix-Navarro, F. Paraguay-Delgado, H. Alvarez-Huerta, S. Pérez-Sicairos and E. Alonso Reynoso-Soto, Journal of Rare Earths, 2017, 35, 259-270.

22 T. Boningari, S. N. R. Inturi, M. Suidan and P. G. Smirniotis, Chem. Eng. J., 2018, 339, 249-258.

23 A. Charanpahari, S. S. Umare, S. P. Gokhale, V. Sudarsan, B. Sreedhar and R. Sasikala, Appl. Catal., A, 2012, 443-444, 96-102. 
24 A. Charanpahari, S. S. Umare and R. Sasikala, Appl. Surf. Sci., 2013, 282, 408-414.

25 F. Dong, H. Wang, G. Sen, Z. Wu and S. C. Lee, J. Hazard. Mater., 2011, 187, 509-516.

26 R. Asahi, T. Morikawa, T. Ohwaki, K. Aoki and Y. Taga, Science, 2001, 293, 269-271.
27 Y. H. Xu, C. Chen, X. L. Yang, X. Li and B. F. Wang, Appl. Surf. Sci., 2009, 255, 8624-8628.

28 C. H. Cao, Adv. Mater. Res., 2012, 488-489, 221-225.

29 W. M. Hou and Y. Ku, J. Alloys Compd., 2011, 509, 5913-5918.

30 W. J. Zhang, M. L. Hu and H. B. He, Adv. Mater. Res., 2012, 457-458, 563-566. 